\title{
Structural Characterization of $\mathrm{N}$-Protonated Amides. Regioselective $\mathrm{N}$-Activation of Medium-Bridged Twisted Lactams
}

\author{
Michal Szostak, Lei Yao, Victor W. Day, Douglas R. Powell, and Jeffrey Aubé \\ Department of Medicinal Chemistry, University of Kansas, Structural Biology Center, 2121 \\ Simons Drive, West Campus, Lawrence, KS 66047
}

\section{Abstract}
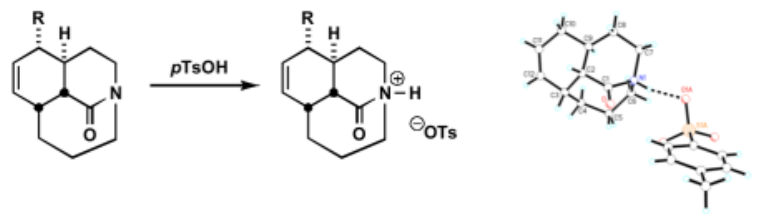

The straightforward protonation of lactams by treatment with acid and the full structural characterization of three resulting $N$-protonated lactams are disclosed. This work provides experimental evidence that $N$-protonation of amide bonds results in a dramatic increase of nonplanarity about the C-N amide bond. The resulting compounds are discussed in structural, spectroscopic, and reactivity terms. The data suggests that ca. $50^{\circ}$ distortion of these amide bonds suffices for their efficient $N$-activation.

Although most amides usually protonate on oxygen, amide $N$-protonation has been nonetheless proposed in a number of biologically relevant mechanisms, ${ }^{1}$ including cis-trans peptide bond isomerization, ${ }^{2}$ amide bond hydrolysis, ${ }^{3}$ and protein splicing. ${ }^{4}$ Although fundamentally different reactivity patterns are expected - and observed - to result from amide subsitution, ${ }^{5}$ the study of $N$-protonated amides has been hampered by the unavailability of molecules that contain them.

The characterization of $\mathrm{N}$-protonated amides is challenging because such species are thermodynamically disfavored relative to their O-protonated isomers by ca. $40 \mathrm{kcal} / \mathrm{mol}{ }^{1}{ }^{1}$ To date, examples of isolated and otherwise unadorned $N$-protonated amides are severely limited to perpendicularly twisted 2-quinuclidone derivatives (Figure 1a). ${ }^{6 a-f}$ In addition, Lectka reported an elegantly designed $N$-protonated amide that was stabilized by the proximity of an additional tertiary amine (Figure $1 \mathrm{~b}$ ). ${ }^{6 \mathrm{~g}}$ To date, only two $\mathrm{N}$-protonated amides have been characterized by X-ray crystallography. ${ }^{7}$ Herein, we demonstrate that a series of medium-bridged $N$-protonated lactams can be readily prepared by acid treatment. This streamlined access to multiple lactam conjugate acids has permitted the full structural characterization of three $\mathrm{N}$-protonated amides and provided the first experimental evidence showing that the $\mathrm{N}$-protonation of amide bonds results in a dramatic increase of pyramidalization around the $\mathrm{C}-\mathrm{N}$ amide bond. ${ }^{8}$ Our data also suggest that ca. $50^{\circ}$ distortion

jaube@ku.edu.

Supporting Information Available: Experimental details, characterization data for new compounds and .cif files of 1d, 3a-c. This material is available free of charge via the Internet at http://pubs.acs.org. 
of amide bonds (where $0^{\circ}$ would correspond to planar amide, $90^{\circ}$ to a fully orthogonal amide bond) suffices for efficient $N$-protonation or alkylation of lactams.

Recent efforts in this laboratory have provided ready access to a family of bridged lactams that are characterized by moderate amide bond distortion (twist values ca. $40-50^{\circ}$ ). ${ }^{9}$ Such compounds display decidedly non-traditional amide bond reactivity patterns that include unusual cleavage reactions of a $\mathrm{C}-\mathrm{N} \sigma$ bond adjacent to the amide bond. ${ }^{9 \mathrm{~d}-\mathrm{f}} \mathrm{We}$ hypothesized that these reactions take place via initial $\mathrm{N}$-alkylation made possible by the increased basicity of the non-planar amide bond nitrogen. The facility of these reactions suggested it might be possible to isolate the responsible species by straightforward protonation or alkylation. Indeed, when tricyclic amides 1a-c were exposed to mild acids, protonation took place at nitrogen to afford the corresponding stable salts in excellent yields (Scheme 1). The tosylates 3a-c were crystalline, and their structures could be confirmed by $\mathrm{X}$-ray crystallography (Figure 2). Table 1 summarizes Winkler-Dunitz distortion parameters $\tau, \chi_{C}$, and $\chi_{\mathrm{N}}$ (describing magnitude of rotation around the $N-\mathrm{C}(\mathrm{O})$ bond, pyramidalization at carbon and pyramidalization at nitrogen, respectively $)^{10}$ and bond lengths of the $N$ protonated lactams.

Notably, the availability of crystal structures of both $\mathbf{1 c}$ and $\mathbf{3 c}$ allowed the neutral amide and its conjugate acid to be easily compared. As expected, $N$-protonation of amide bonds enhances the pyramidal character at nitrogen $\left(\chi_{N}\right)$. The resulting change is substantial: from a moderately pyramidal to practically $\mathrm{sp}^{3}$ hybridized nitrogen (in series $\mathbf{c} \chi_{\mathrm{N}}$ increases from $36.1^{\circ}$ to $52.1^{\circ}$ ). This is accompanied by the flattening of the $\mathrm{C}=\mathrm{O}$ carbon (in series $\mathbf{c} \chi_{\mathrm{C}}$ drops from $12.8^{\circ}$ to $1.4^{\circ}$ ) and a dramatic decrease in C-N bond planarity (in $2 \mathbf{c} \tau$ is $81.9^{\circ}$, cf. $51.5^{\circ}$ for $\left.1 \mathrm{c}\right)$. The bond lengths were also influenced by $N$-protonation. The $N-\mathrm{C}(\mathrm{O})$ bond experiences significant lengthening (in $1 \mathrm{c}$ by $0.115 \AA$ ), while the $\mathrm{C}=\mathrm{O}$ bond was moderately shortened (in 1c by $0.026 \AA$ ). Overall, these structural changes indicate substantial rehybridization upon $\mathrm{N}$-protonation and C-N bond rotation, even in the fairly rigid tricyclic ring system of $1.8 \mathrm{a}, \mathrm{b}$

Furthermore, the $\mathrm{X}$-ray structures reveal that the $\mathrm{N}$-protons are stabilized by hydrogen bonding to tosylate oxygens (Figure 2). The O1A-H1 (O3A-H1) distances of 1.79-1.82 and the N1-H1-O1A (N1-H1-O3A) angles of $163-177^{\circ}$ are consistent with the presence of moderately strong hydrogen bonds. The bond distances between the amide bond nitrogens and tosylate oxygens in salts $3 \mathrm{a}-3 \mathrm{c}(2.68-2.72 \AA)$ also support the formation of mediumstrength hydrogen bonds engaging the amide nitrogen atoms. ${ }^{11}$

We earlier reported that tricyclic lactams react with MeI to form the corresponding amidinium salts followed by regioselective $\mathrm{S}_{\mathrm{N}} 2$ displacement with iodide. ${ }^{9 \mathrm{e}}$ As expected, similar chemistry was observed upon exposure of tricyclic amides to related electrophiles under mild conditions (Scheme 2a, see SI for details). In contrast, treatment with Meerwein's reagent, lacking a nucleophilic counterion, permitted isolation of two rare examples of $N$-alkylated amides (Scheme $2 \mathrm{~b}$ ). ${ }^{12}$ Unfortunately, we were not able to obtain high-resolution crystal structures of these compounds.

Our attempts to similarly protonate or alkylate [4.3.1] bicyclic lactams like 1d revealed differences in reactivity between these species and their tricyclic cousins 3a-c (Scheme 2c). For example, 1d did not readily form a salt upon room-temperature treatment with acid or MeI However, under forcing conditions 1d did afford products resulting from $N$-methylation followed by $\mathrm{I}^{-}$displacement (Scheme $2 \mathrm{c}, \mathrm{R}=\mathrm{Ph}$, see SI for details). Control reactions confirmed that both the bridged structure and the alkylating agent were necessary for this reaction. Comparison of twist parameters for the bicyclic and tricyclic lactams suggests that a twist angle of $\geq 50^{\circ}$ is required for efficient $\mathrm{N}$-protonation and $\mathrm{N}$-alkylation of amide 
bonds ${ }^{8 \mathrm{a}, \mathrm{b}}$ although a twist angle of ca. $40^{\circ}$ may be sufficient to result in $\mathrm{N}$-alkylation under suitably vigorous conditions.

In summary, this work demonstrates that the $N$-protonation of amide bonds results in a dramatic increase of distortion around the $\mathrm{N}-\mathrm{C}(\mathrm{O})$ bond. Furthermore, even moderately distorted amide bonds participate in electrophilic $N$-activation of amides. Studies on general activation of amide bonds are underway.

\section{Supplementary Material}

Refer to Web version on PubMed Central for supplementary material.

\section{Acknowledgments}

This work was supported by the National Institute of General Medical Sciences (GM-49093). We thank Dr. Kevin Frankowski for helpful suggestions.

\section{References}

1. Greenberg, A.; Breneman, CM.; Liebman, JF. Amide Linkage: Selected Structural Aspects in Chemistry, Biochemistry, and Materials Science. Wiley; New York: 2000.

2. (a) Harrison RK, Stein RL. Biochemistry. 1990; 29:1684-1689. [PubMed: 2184885] (b) Liu J, Albers MW, Chen CM, Schreiber SL, Walsh CT. Proc Natl Acad Sci U S A. 1990; 87:2304-2308. [PubMed: 2179953] (c) Fischer G. Chem Soc Rev. 2000; 29:119-127. (d) Cox C, Lectka T. Acc Chem Res. 2000; 33:849-858. [PubMed: 11123884] (e) Eakin CM, Berman AJ, Miranker AD. Na Struct Mol Biol. 2006; 13:202-208.

3. (a) Williams A. J Am Chem Soc. 1976; 98:5645-5651. (b) Somayaji V, Brown RS. J Org Chem. 1986; 51:2676-2686. (c) Perrin CL. Acc Chem Res. 1989; 22:268-275. (d) Brown RS, Bennet AJ, Slebocka-Tilk H. Acc Chem Res. 1992; 25:481-488. (e) Mujika JI, Mercero JM, Lopez X. J Am Chem Soc. 2005; 127:4445-4453. [PubMed: 15783227] (f) Mujika JI, Formoso E, Mercero JM, Lopez X. J Phys Chem B. 2006; 110:15000-15011. [PubMed: 16869615]

4. (a) Poland BW, Xu MQ, Quiocho FA. J Biol Chem. 2000; 275:16408-16413. [PubMed: 10828056] (b) Romanelli A, Shekhtman A, Cowburn D, Muir TW. Proc Natl Acad Sci U S A. 2004; 101:6397-6402. [PubMed: 15087498] (c) Shemella P, Pereira B, Zhang YM, Van Roey P, Belfort G, Garde S, Nayak SK. Biophys J. 2007; 92:847-853. [PubMed: 17085503] (d) Johansson DGA, Wallin G, Sandberg A, Macao B, Aqvist J, Hard T. J Am Chem Soc. 2009; 131:9475-9477. [PubMed: 19534521]

5. (a) Shimada T, Nakamura I, Yamamoto Y. J Am Chem Soc. 2004; 126:10546-10547. [PubMed: 15327305] (b) Ito M, Sakaguchi A, Kobayashi C, Ikariya T. J Am Chem Soc. 2007; 129:290-291. [PubMed: 17212405] (c) Ueno S, Chatani N, Kakiuchi F. J Am Chem Soc. 2007; 129:6098-6099. [PubMed: 17444647] (d) Kajita Y, Matsubara S, Kurahashi T. J Am Chem Soc. 2008; 130:60586059. [PubMed: 18412348] (e) Yoshino Y, Kurahashi T, Matsubara S. J Am Chem Soc. 2009; 131:7494-7495. [PubMed: 19435347]

6. (a) Levkoeva EI, Nikitskaya ES, Yakhontov LN. Dokl Akad Nauk. 1970; 192:342-345. (b) Levkoeva EI, Nikitskaya ES, Yakhontov LN. Khim Geterotsikl Soedin. 1971:378-384. (c) Pracejus H. Ber. 1959; 92:988-998. (d) Pracejus H. Ber. 1965; 98:2897-2905. (e) Pracejus H, Kehlen M, Kehlen H, Matschin H. Tetrahedron. 1965; 21:2257-2270. (f) Tani K, Stoltz BM. Nature. 2006; 441:731-734. [PubMed: 16760973] (g) Cox C, Wack H, Lectka T. Angew Chem, Int Ed. 1999; 38:798-800.

7. (a) See, references $6 f$ and $6 \mathrm{~g}$. (b) Note that Kirby et al. described protonated 2-azaadamantanone in its hydrated form. Kirby AJ, Komarov IV, Feeder N. J Chem Soc, Perkin Trans. 2001; 2:522-529.

8. (a) Greenberg A, Venanzi CA. J Am Chem Soc. 1993; 115:6951-6957. (b) Greenberg A, Moore DT, DuBois TD. J Am Chem Soc. 1996; 118:8658-8668. (c) Laidig KE, Cameron LM. Can J Chem. 1993; 71:872-879. (d) Mo YR, Schleyer PV, Wu W, Lin MH, Zhang Q, Gao JL. J Phys 
Chem A. 2003; 107:10011-10018. (e) Kemnitz CR, Loewen MJ. J Am Chem Soc. 2007; 129:25212528. [PubMed: 17295481]

9. (a) Yao L, Aubé J. J Am Chem Soc. 2007; 129:2766-2767. [PubMed: 17302421] (b) Szostak M, Yao L, Aubé J. Org Lett. 2009; 11:4386-4389. [PubMed: 19722508] (c) Szostak M, Yao L, Aubé J. J Org Chem. 2009; 74:1869-1875. [PubMed: 19178141] (d) Szostak M, Aubé J. Org Lett. 2009; 11:3878-3881. [PubMed: 19708701] (e) Lei Y, Wrobleski AD, Golden JE, Powell DR, Aubé J. J Am Chem Soc. 2005; 127:4552-4553. [PubMed: 15796502] (f) Szostak M, Aubé J. Chem Commun. 2009:7122-7124. (g) Szostak M, Yao L, Aubé J. J Am Chem Soc. 2010; 132:2078-2084. [PubMed: 20095610] For reviews on bridged amides, see: (h) Hall HK, Elshekeil A. Chem Rev. 1983; 83:549-555. (i) Clayden J, Moran WJ. Angew Chem, Int Ed. 2006; 45:7118-7120.

10. Winkler FK, Dunitz JD. J Mol Biol. 1971; 59:169-182. [PubMed: 5283751]

11. Formation of the $N$-protonated amides is also evident from changes in the ${ }^{13} \mathrm{C} N M R$ and IR spectra. See Table B in the SI for details.

12. To the best of our knowledge only three examples of isolated $\mathrm{N}$-alkylated amides have been reported to date (Ref. ${ }^{6 a}, 6 e$ and ${ }^{7 b}$ ). In contrast to the current study, all of these lactams contained perfectly perpendicular amide bonds. For an elegant study on the methylation of quinuclidone derivatives, see: Werstiuk NH, Brown RS, Wang Q. Can J Chem. 1996; 74:524-532. 

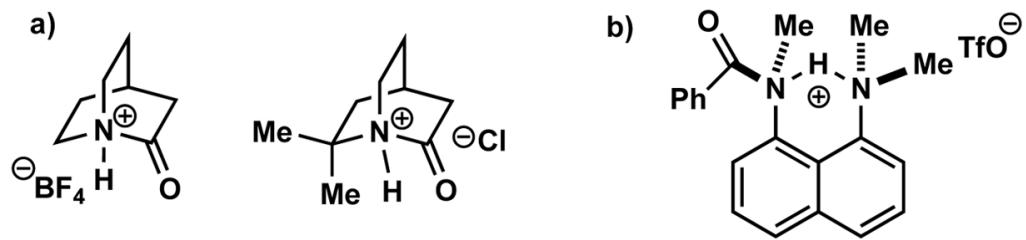

Figure 1.

Previously reported examples of isolated $N$-protonated amides. 
(a)

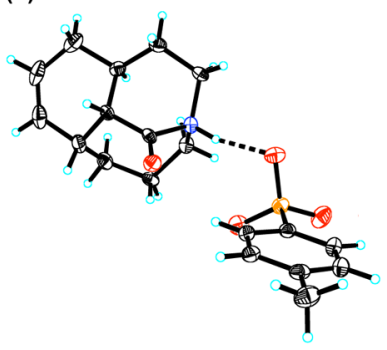

(b)

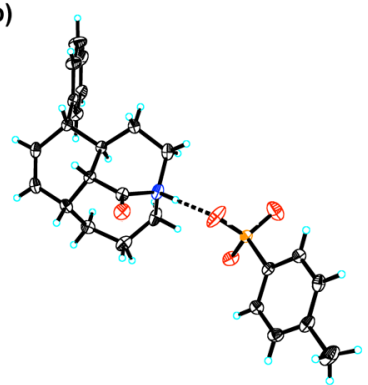

(c)

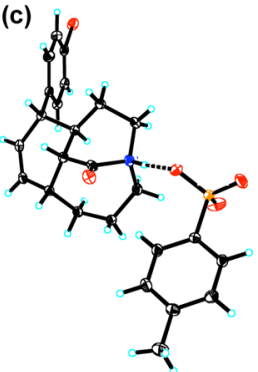

Figure 2.

Crystal structures of (a) 3a, (b) 3b, and (c) 3c. Selected bond lengths [ $\AA$ ] and angles $\left[{ }^{\circ}\right]$ : (a) N1-C1, 1.492(3), C1-O1, 1.202(4), C1-C2, 1.489(4), N1-H1, 0.93, C7-N1-C1-O1, -121.5(5) ${ }^{\circ}$; C6-N1-C1-O1, 111.1(5) ${ }^{\circ}$; C7-N1-C1-C2, 59.3(3) ${ }^{\circ}$; C6-N1-C1-C2, -68.2(3) ${ }^{\circ}$. (b) N1-C1, 1.491(3), C1-O1, 1.197(3), C1-C2, 1.487(4), N1-H1, 0.86(4), C7-N1-C1-O1, -126.3(3) ${ }^{\circ}$; C6-N1-C1-O1, 106.2(3) ${ }^{\circ}$; C7-N1-C1-C2, 56.1(3) ; C6-N1-C1-C2, -71.5(3) . (c) N1-C1, 1.502(2), C1-O1, 1.192(2), C1-C2, 1.488(3), N1-H1, 0.89(3), C7-N1-C1-O1, -124.84(18) ${ }^{\circ}$; C6-N1-C1-O1, 107.21(19) ${ }^{\circ}$; C7-N1-C1-C2, 56.58(19) ${ }^{\circ}$; C6-N1-C1-C2, $-71.38(19)^{\circ}$. 


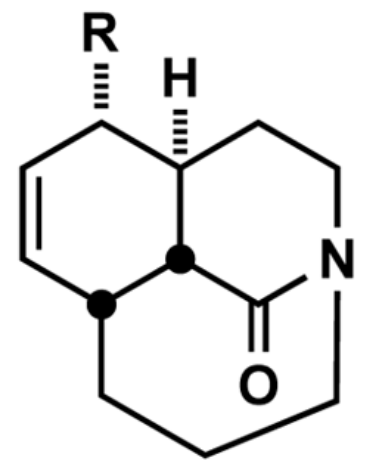

(1a) $\mathrm{R}=\mathrm{H}$

(1a) $R=H$

(1b) $R=P h$

(1c) $\mathrm{R}=4-\mathrm{BrC}_{6} \mathrm{H}_{4}$

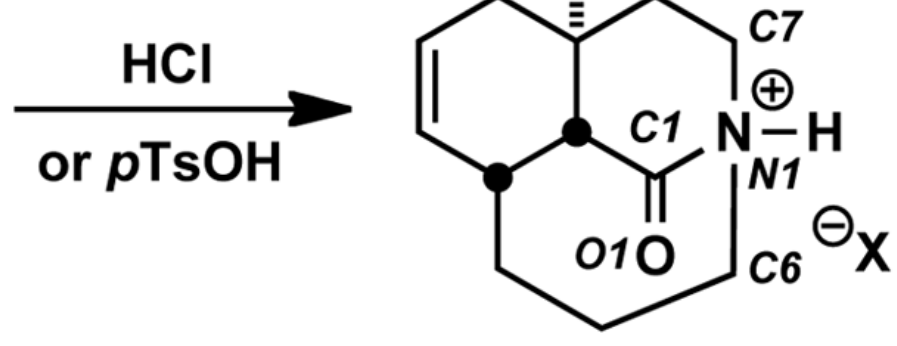

(2a) $\mathrm{X}=\mathrm{Cl}, 57 \%$

(3a) $X=$ OTs, $99 \%$

(3b) $X=0 T s, 96 \%$

(3c) $X=0 T s, 96 \%$

Scheme 1. 
a

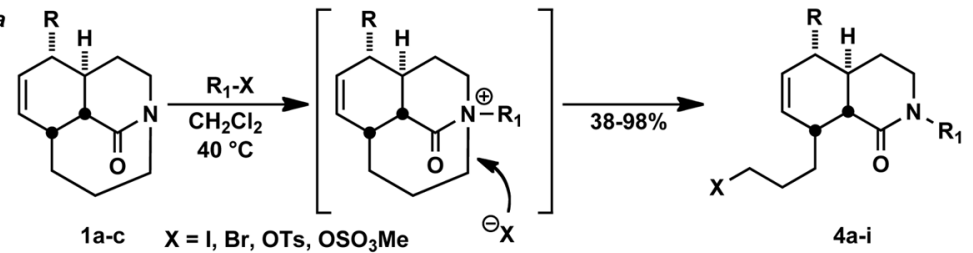

b $\mathbf{R}$
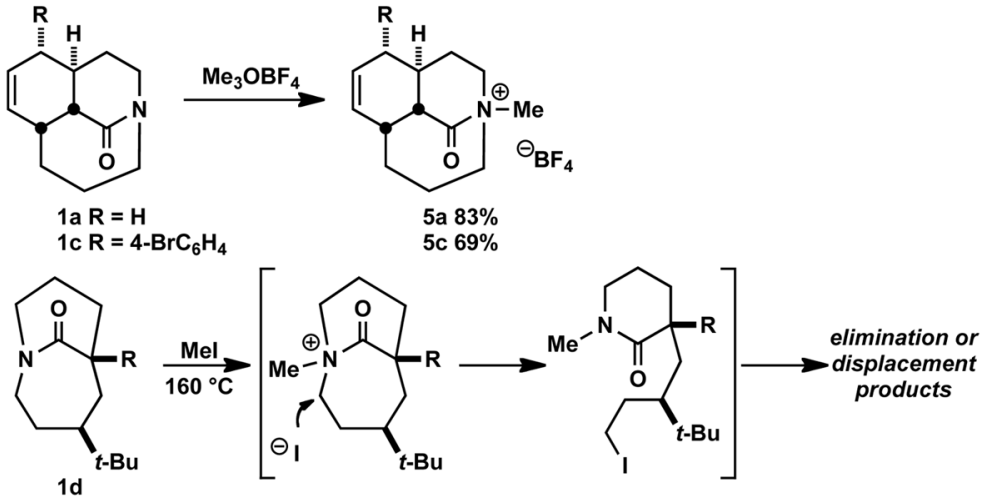

Scheme 2. 
